\title{
Synthesis of MgO Nanoparticles from Different Organic Precursors; Catalytic Decontamination of Organic Pollutants and Antitumor Activity
}

Islam MI Moustafa ${ }^{1 *}$, Ihab A Saleh ${ }^{1}$ and Mohamed R Abdelhamid ${ }^{2}$

${ }^{1}$ Chemistry Department, Faculty of Science, Benha University, 13518, Egypt

${ }^{2}$ Department of Medicine and Hepatology, Faculty of Medicine, Minia University, Egypt

\begin{abstract}
The present work deals with the synthesis of nanostructured $\mathrm{MgO}$ from different organic precursors, by a facile precipitation method as catalysts for the decontamination of Malathion (stimulant of chemical warfare agents) (VX) and orange $\mathrm{G}$ as organic pollutants. The as-prepared nanoparticles were obtained by thermal decomposition of the oxalate, tartarate, citrate, succinate, malate, malonate and glycinate precursors at $\approx 650^{\circ} \mathrm{C}$ and were characterized by thermal analysis, FTIR, X-ray diffraction, high resolution transmission electron microscope (HRTEM) and absorption spectra. The morphology and crystal sizes were found to be highly affected by the starting organic precursors. The results revealed that the prepared inexpensive magnesium oxides have high potential as catalysts for photo degradation of both Malathion and orange $\mathrm{G}$ from water samples. Inhibitory activity against Breast Carcinoma MCF-7 cell line was detected using some selected nanosized $\mathrm{MgO}$ and compared to that of Vinblastine as a standard drug.
\end{abstract}

Keywords: Nano sized MgO; Catalytic photo degradation; VX stimulant (Malathion); Orange G; Antitumor activity

\section{Introduction}

Researches on the synthesis and application of nanomaterials had experienced tremendous growth in recent years, owing to their unique properties making them suitable for applications in almost every field of science [1-11]. Photocatalytic degradation of dyes and toxic organic materials from aqueous solution is considered one of the most effective methods for water treatment especially using nanosized metal oxides as catalysts [12-18]. Nanocrystalline $\mathrm{MgO}$ is an interesting functional material due to its low heat capacity, chemical inertness, optical transparency and high thermal stability. Due to its high surface area, it is used as an efficient adsorbent for numerous toxic chemicals and acid gases. Recently, MgO nanoparticles have shown promise for application in tumor treatment and also have considerable potential as an antibacterial agent [19-24]. In the present work and in continuity to our previous work [25], we study the effect of starting organic precursors on the crystal size and morphology of nanosized $\mathrm{MgO}$. The prepared nanooxides were tested successfully as adsorbents for the decontamination of Malathion as stimulant of chemical warfare agents (CWA) (VX) and orange G as organic pollutant. Inhibitory activity against Breast Carcinoma MCF-7 cell line was also tested using some selected nanosized $\mathrm{MgO}$.

\section{Experimental Section}

\section{Synthesis of magnesium oxide nanoparticles}

AR grade chemicals obtained from Merck and Aldrich were used for the preparation of the nano particles of magnesium oxide (M1-M7). The individual oxides were prepared via the precipitation method by titration of $50 \mathrm{ml}$ of $0.1 \mathrm{M}$ magnesium acetate drop by drop to $50 \mathrm{ml}$ of $0.2 \mathrm{M}$ of different organic acids viz. oxalic acid (M1), tartaric acid (M2), citric acid (M3), succinic acid (M4), malic acid (M5), malonic acid (M6) and glycine (M7), respectively. The mixtures were stirred for $1 \mathrm{hr}$. and the precipitates formed were filtered, washed thoroughly using bidistilled water, air dried, thoroughly grounded in agate mortar and finally dried at $120^{\circ} \mathrm{C}$ for two hours in the form of fine powder. The powder so obtained was annealed at $650^{\circ} \mathrm{C}$ for six hours in muffle furnace to obtain the corresponding nanosized magnesium oxides.

\section{Physical measurements}

FT-IR spectra of both of the precipitated and ignited samples were recorded on a Nicolet iSio FT-IR spectrophotometer in the $4000-400 \mathrm{~cm}^{-1}$ region using $\mathrm{KBr}$ disk technique (Chemistry department, Faculty of science, Benha University, Egypt). Electronic absorption spectra of the prepared nanooxides were recorded on a Jasco (V-530) UV-Vis spectrophotometer (Chemistry department, Faculty of Science, Benha University, Egypt). Thermogravimetric analysis (TG-DT) for the organic precursors was recorded on Shimadzu TA-60 WS thermal analysis (Micro analytical unit, Menofia University, Shebin El-Kom, Egypt). Elemental analysis for $\mathrm{C}$ and $\mathrm{H}$ of the nanooxides were carried out using Elementer Vario EL III Carlo Erba 1108 instrument (The Regional Center for Mycology and Biotechnology, Al-Azhar University, Cairo, Egypt). X-ray powder diffraction (XRD) was recorded on a $18 \mathrm{~kW}$ diffractometer (Bruker; model D8 Advance) with monochromated $\mathrm{Cu} \mathrm{K}_{\alpha}$ radiation $(\lambda) 1.54178$ $\AA$ (Central metallurgical research institute, Helwan, Egypt). The HR-TEM images of some selected nanooxides were taken on a transmission electron microscope (JEOL; model $1200 \mathrm{EX}$ ) at an accelerator voltage of $220 \mathrm{kV}$ (Egyptian Petroleum Research Institute, Cairo, Egypt).

\section{Photocatalytic degradation of Orange G dye}

For a typical photocatalytic experiment, $100 \mathrm{mg}$ of the nanosized photocatalyst was added to $25 \mathrm{ml}$ of $20 \mathrm{ppm}$ aqueous dye solution which was kept in dark for 6 hrs to allow the system to reach an adsorption desorption equilibrium then $2 \mathrm{ml}$ of $0.5 \mathrm{M}$ hydrogen peroxide solution was added. The degradation process was investigated in a Pyrex beaker under the UV illumination using a $250 \mathrm{~W}$ xenon arc lamp (Thoshiba, SHLS-002) $(\lambda=365 \mathrm{~nm})$. After recovering the catalyst by centrifugation,

*Corresponding author: Islam MI Moustafa, Chemistry Department, Faculty of Science, Benha University, 13518, Egypt, Tel/Fax: +201333222578; E-mail: islamshahin84@outlook.com

Received June 28, 2017; Accepted July 06, 2017; Published July 16, 2017

Citation: Moustafa IMI, Saleh IA, Abdelhamid MR (2017) Synthesis of MgO Nanoparticles from Different Organic Precursors; Catalytic Decontamination of Organic Pollutants and Antitumor Activity. J Material Sci Eng 6: 359. doi: 10.4172/2169-0022.1000359

Copyright: @ 2017 Moustafa IMI, et al. This is an open-access article distributed under the terms of the Creative Commons Attribution License, which permits unrestricted use, distribution, and reproduction in any medium, provided the original author and source are credited. 
the absorption spectra of the clear solution was measured at $485 \mathrm{~nm}$ $\left(\lambda_{\max }\right.$ for Orange $\mathrm{G}$ dye) at different time intervals using a UV-Vis spectrophotometer.

\section{Photocatalytic degradation of Malathion}

The photocatalytic degradation of $0.06 \mathrm{ml} / \mathrm{l}$ of Malathion solution was performed using the smallest crystal sized magnesium oxide (M7) sample (prepared from glycine). For a typical experiment, $100 \mathrm{mg}$ of the nanooxide sample was added to $25 \mathrm{ml}$ of $0.06 \mathrm{ml} / \mathrm{l}$ Malathion solution which was kept in dark for 6 hrs. The degradation process was investigated as previously mentioned for Orange $\mathrm{G}$ dye and the concentration of the remaining pollutant was followed up by measuring absorption spectra at $238,265 \mathrm{~nm}\left(\lambda_{\max }\right.$ for Malathion) at different time intervals.

\section{Antitumor activity}

Antitumor activity against Breast Carcinoma MCF-7 cell line was measured for some selected samples at The Regional Center for Mycology and Biotechnology, Al-Azhar University, Cairo, Egypt and compared to that of Vinblastine as a standard drug. The number of viable cells and the percentage of viability were calculated as $\left(1-\frac{O D t}{O D c}\right) \times 100$; where ODt is the mean optical density of the wells treated with the tested samples and ODc is the mean optical density of the untreated cells. The relation between surviving cells and drug concentration is plotted to get the survival curve of each tumor cell line after treatment with the nanooxides. The $50 \%$ inhibitory concentration $\left(\mathrm{IC}_{50}\right)$, the concentration required to cause toxic effect in $50 \%$ of intact cells, was estimated from graphic plots of the dose response curve for each concentration.

\section{Results and Discussion}

\section{Characterization}

Thermogravimetric analysis: The thermogravimetric-differential thermal analysis was performed on the organic precursors to follow their thermal decomposition to the final oxide forms. Inspection of the thermograms (Figure 1) showed that the organic precursors were thermally degraded through three main steps. The first within the temperature range $66.75-184.78^{\circ} \mathrm{C}$ due to the dehydration of humidity and crystallinity water (this step is sometimes a composite of two steps). The beginning of the thermal degradation of the unhydrous compounds took place within the second step within the temperature range $114.72-344.33^{\circ} \mathrm{C}$ by the evolution of gases such as $\mathrm{N}_{2}$ and $\mathrm{CO}_{2}$. Complete decomposition of the organic precursors occurred in the third step within the range $232.99-565.99^{\circ} \mathrm{C}$ which led to the formation of the nanosized $\mathrm{MgO}$ as final product. Example of thermal decomposition process of tartaric acid precursor is represented as:

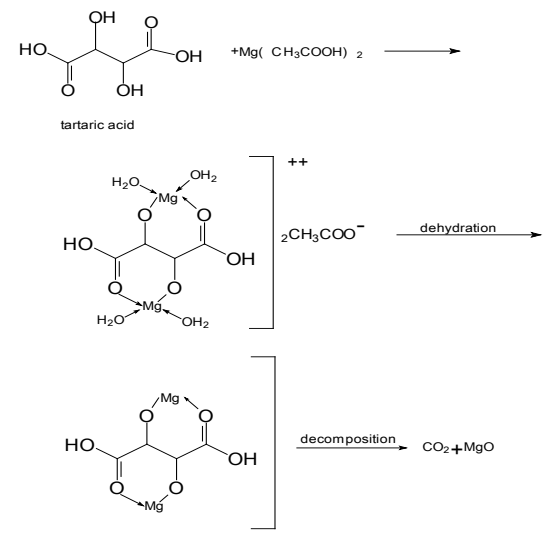

Fourier transforms infrared spectra (FTIR): The FTIR spectra of the magnesium-organic precursors were studied and compared to those of the corresponding nanooxides. The most important band frequencies $\left(\mathrm{cm}^{-1}\right)$ are listed in Table 1 . The spectra of the organic precursors show weak absorption bands within the wavenumber ranges $3373-3430 \mathrm{~cm}^{-1}$ and $1033-1171 \mathrm{~cm}^{-1}$ due to the stretching and bending vibrations of the trace water molecule, respectively. These two bands appeared within the ranges $2955-3430 \mathrm{~cm}^{-1}$ and $1032-1176 \mathrm{~cm}^{-1}$ as very weak bands in the spectra of the ignited samples. The strong bands within the range $1570-1677 \mathrm{~cm}^{-1}$ are due to the stretching vibration of $\mathrm{C}=\mathrm{O}$ group $\left(V_{\mathrm{C}=\mathrm{O}}\right)$. These bands, more or less, disappeared in case of calcinated samples. It is worthy to mention that there is a shift in the IR active mode, which is due to nano size grain. For a nano size grain, the atomic arrangement on the boundaries differ greatly from that of the bulk crystals, both in coordination number and bond lengths, showing some extent of disorder [26]. Crystal symmetry is thus, degraded in nano size grains. The degradation in crystal symmetry results in the shifting of the IR active mode [27].

$\mathrm{X}$-ray diffraction analysis (XRD): The X-ray diffraction patterns of the nano sized magnesium oxides are shown in Figure 2. The XRD sharp lines reveal that the oxide nanoparticles are crystalline. The relative crystalline sizes are determined from the XRD lines broadening using the Scherrer equation [28]. From calculation, the average crystalline size was found to be $44.8,33.94,44.60,46.32,47.16,60.80$ and $53.64 \mathrm{~nm}$ for magnesium oxides (M1-M7), respectively (Table 2). The phase purity of all the samples was established by comparison of the X-ray diffraction patterns with JCPDS international data value.

High resolution transmission electron microscopy (HRTEM): The micro structural analysis of the synthesized samples calcined at $650^{\circ} \mathrm{C}$ for 6 hours was investigated using HRTEM. The HRTEM images of some selected samples are shown in Figure 3. It can be seen from the graphs that magnesium nanoparticles have narrow size distribution and are rectangular rode shapes with weak agglomeration. The average particle sizes ranged from $33.93-60.80 \mathrm{~nm}$.

Optical analysis: A fundamental property of nanosized metal oxides is the band gap energy. The band gap energy is the energy separation between the filled valence band and the empty conduction band. Optical excitation of electrons across the band gap is strongly allowed, producing an abrupt increase in the absorption at the wavelength corresponding to the band gap energy. The UV-Visible spectra allow direct determination of band gap using the relation

\begin{tabular}{|c|c|c|c|c|c|}
\hline \multirow[t]{2}{*}{ Compound } & \multicolumn{5}{|c|}{ IR frequency $\left(\mathrm{cm}^{-1}\right)$} \\
\hline & $v_{\mathrm{OH}}$ & $\delta_{\mathrm{OH}}$ & $V_{\mathrm{c}=\mathrm{o}}$ & $v_{\mathrm{c}-\mathrm{o}}$ & $\mathrm{Mg}-\mathrm{O}$ \\
\hline Mg-oxalate & $3389_{b r}$ & 1128.96 & 1637 & 829.92 & 501 \\
\hline NP (M1) & $2955_{v w}$ & 1166.68 & --- & --- & 541 \\
\hline Mg-tartarate & $3408_{b r}$ & 1090.45 & 1617 & 832.88 & 486 \\
\hline NP (M2) & $2979_{v . w}$ & 1135.71 & --- & -- & 542 \\
\hline Mg-citrate & 3425.52 & 115.64 & 1624 & 885 & 544 \\
\hline NP (M3) & $3430_{v \cdot w}$ & 1085 & --- & --- & 553 \\
\hline Mg-succinate & 3430.71 & 1176.47 & 1691 & 893.54 & 522 \\
\hline NP (M4) & $3110_{v . w}$ & 1152.45 & -- & --- & 544 \\
\hline Mg-malate & $3404.33_{\mathrm{br} .}$ & 1084.14 & 1570 & 870.23 & 579 \\
\hline NP (M5) & $3052_{v, w}$ & 1171.25 & -- & --- & 570 \\
\hline Mg-malonate & 3428 & 1032.77 & 1677 & 913.15 & 586 \\
\hline NP (M6) & $3362_{b r}$ & 1136.70 & --- & --- & 583 \\
\hline Mg-glycinate & $3373_{\mathrm{br}}$ & 1033.78 & 1617 & 924.83 & 512 \\
\hline NP (M7) & 3381 & 1095.12 & --- & --- & 522 \\
\hline
\end{tabular}

Table 1: IR frequencies $\left(\mathrm{cm}^{-1}\right)$ of some important groups in the organic precursors and the corresponding nanooxides. 


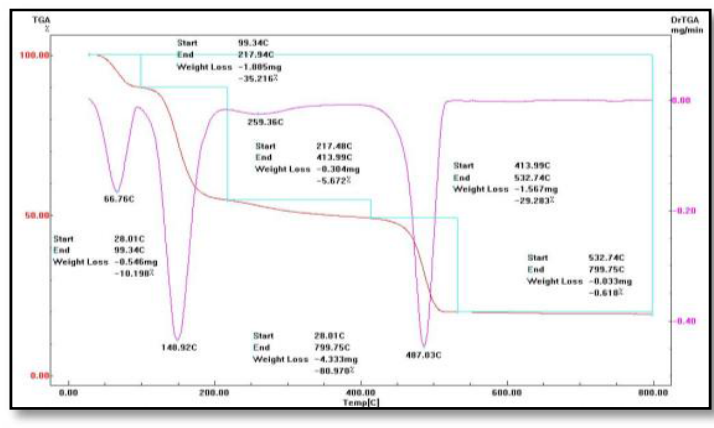

M1

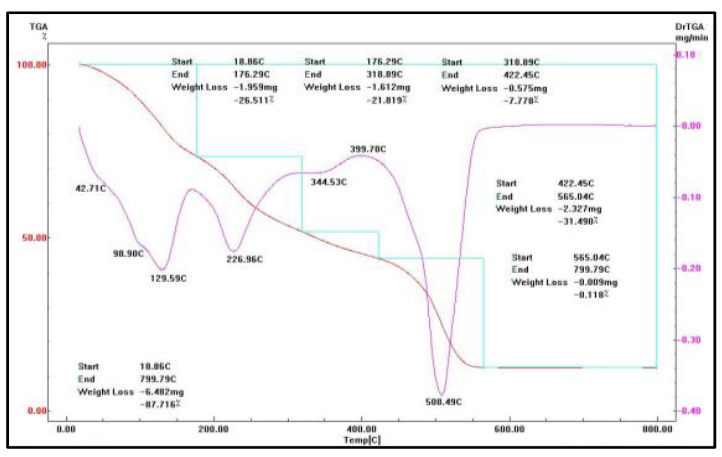

M3

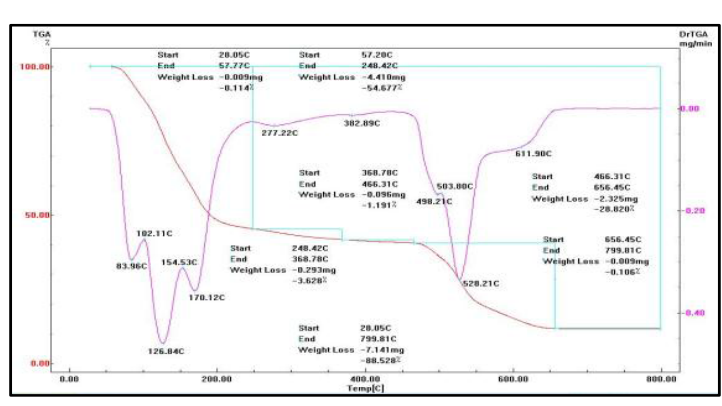

M5

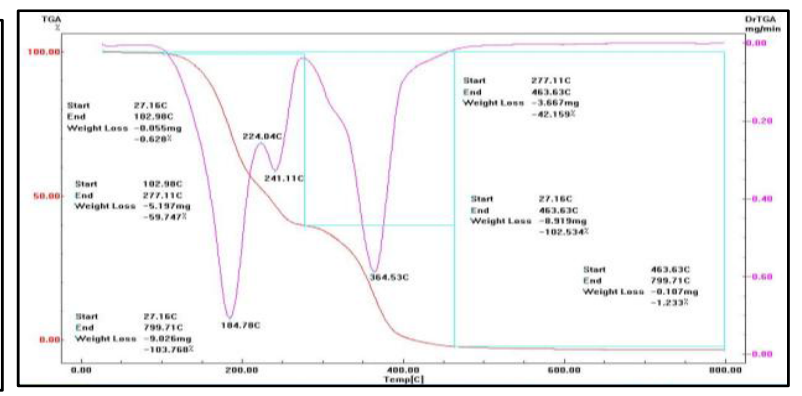

M6

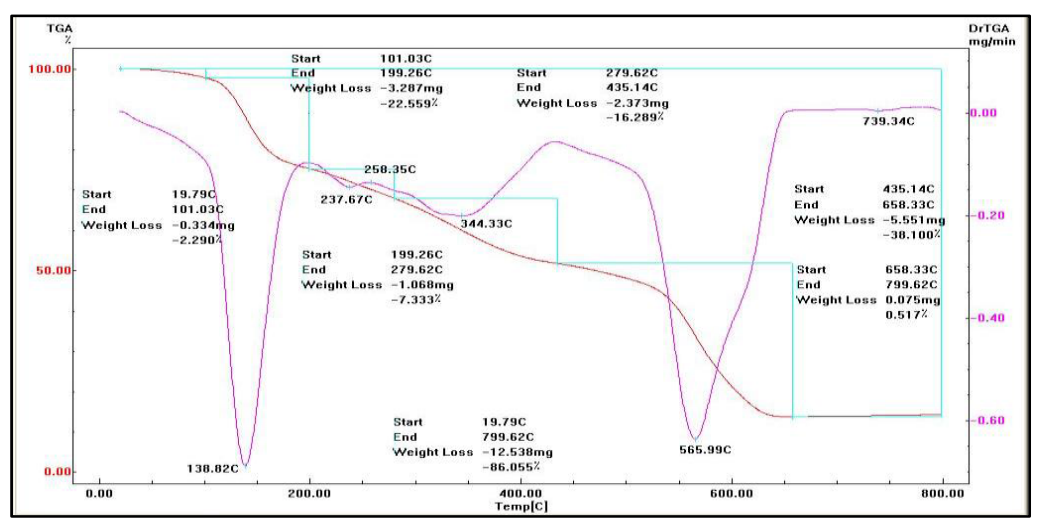

M7

Figure 1: TGA-DTA curves for precursors M1- M7 


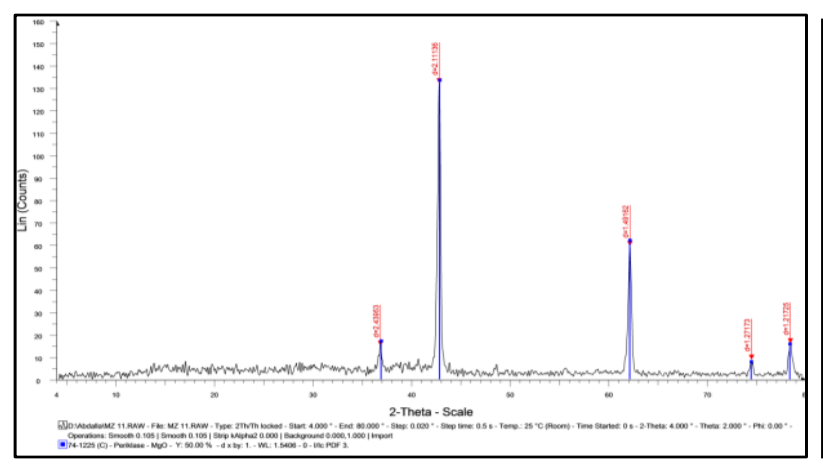

M1

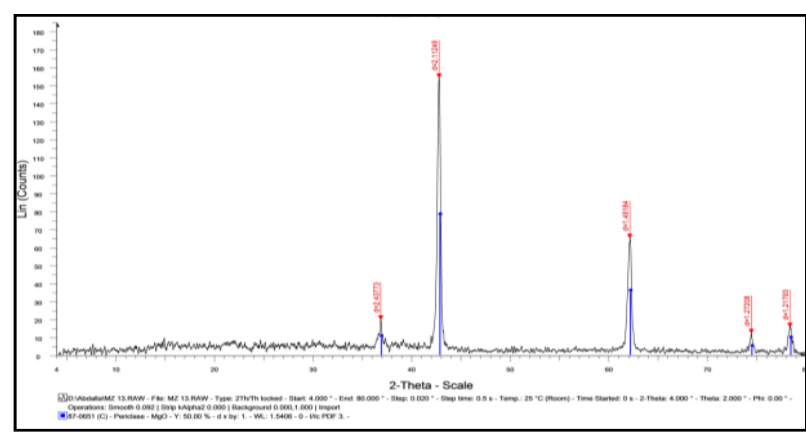

M3

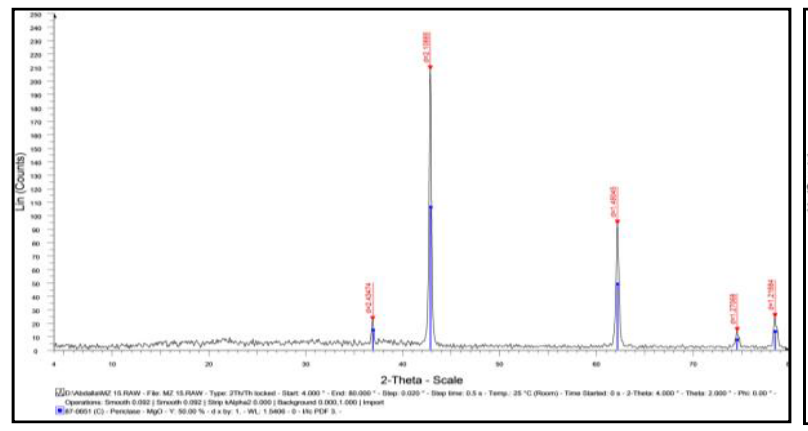

M5

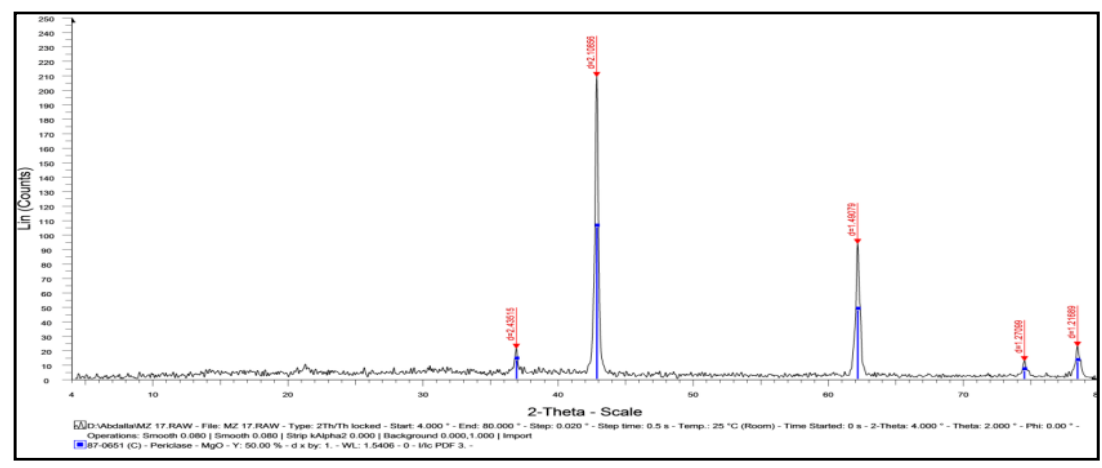

M7

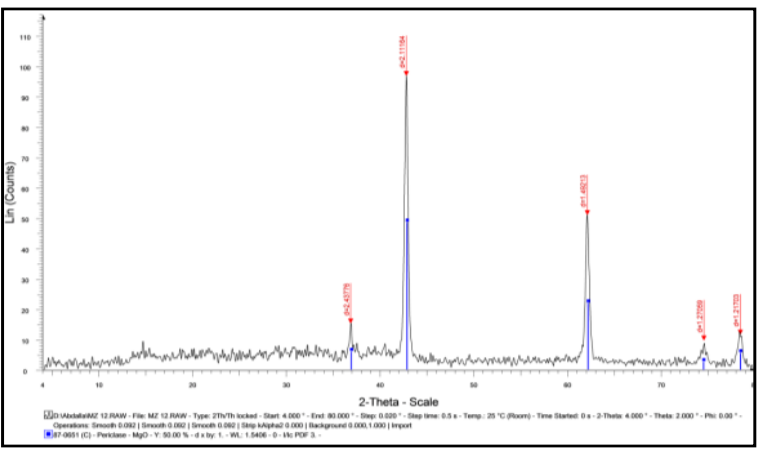

M2

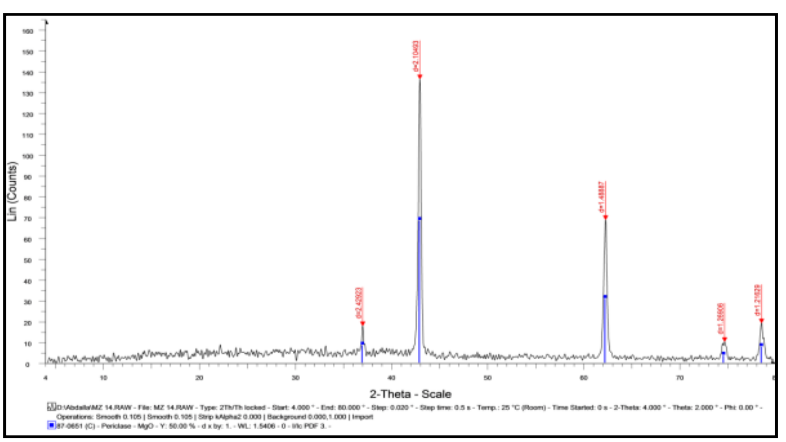

M4

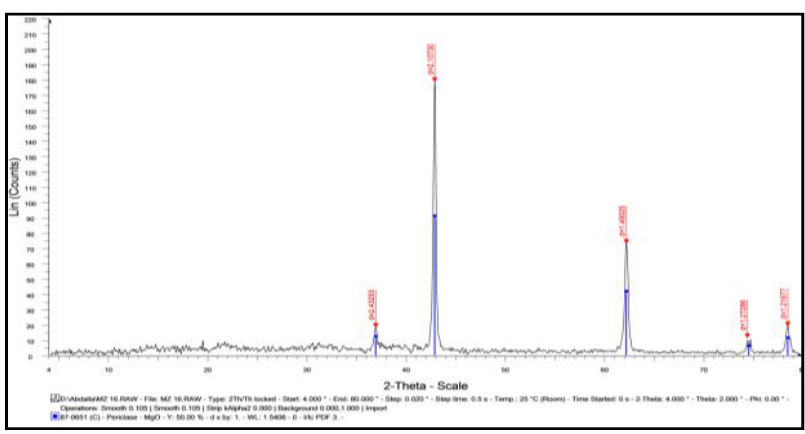

M6

Figure 2: XRD of the samples M1- M7 prepared from organic precursors. 
Citation: Moustafa IMI, Saleh IA, Abdelhamid MR (2017) Synthesis of MgO Nanoparticles from Different Organic Precursors; Catalytic Decontamination of Organic Pollutants and Antitumor Activity. J Material Sci Eng 6: 359. doi: 10.4172/2169-0022.1000359

Page 5 of 8

\begin{tabular}{|c|c|c|c|c|c|}
\hline Sample & Precursor & crystal size (nm) & Phase produced by XRD & Card No. \\
\hline M1 & Oxalate & 44.80 & Periclase-MgO & $01-074-1225$ \\
\hline M2 & Tartarate & 33.94 & Periclase-MgO & $01-087-0651$ \\
\hline M3 & Citrate & 44.60 & Periclase-MgO & $01-087-0651$ \\
\hline M4 & Succinate & 46.32 & Periclase-MgO & $01-087-0651$ \\
\hline M5 & Malate & 47.16 & Periclase-MgO & $01-087-0651$ \\
\hline M6 & Malonate & 60.80 & Periclase-MgO & $01-087-0651$ \\
\hline M7 & Glycinate & 53.64 & Periclase-MgO & Cubic \\
\hline
\end{tabular}

Table 2: Effect of organic acids and glycine precursors on the crystal size and morphology of the prepared nanooxides.

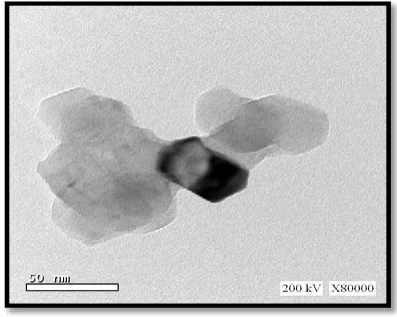

M1

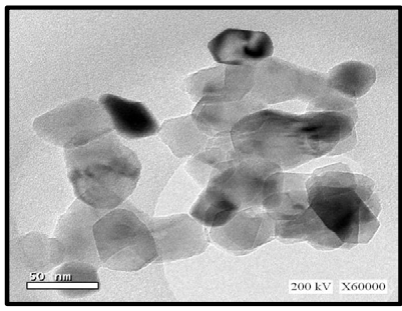

M5

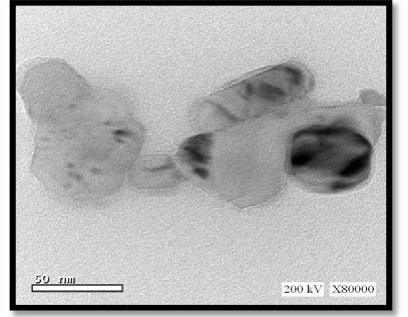

M3

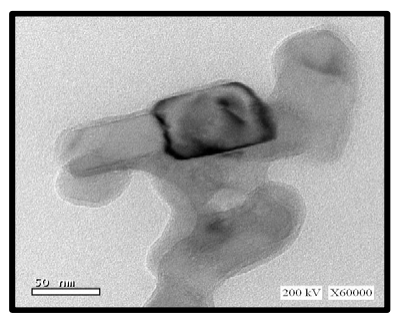

M7
Figure 3: HRTEM of some selected samples.

between the absorption coefficient ( $\alpha$ ) and the incident photon energy $(h v)$ represented by Tauc equation [29]:

$(\alpha h v)=A(h v-E g)^{n}$

Where, $\mathrm{A}$ is a constant, $\mathrm{E}_{\mathrm{g}}$ is the band gap of the material and exponent $\mathrm{n}$ depends on the type of transition, $\mathrm{n}$ is either 2 for an indirect transition or $1 / 2$ for a direct transition. Here the transition is direct so, $\mathrm{n}$ is taken to be $1 / 2$. The value of optical band gap is calculated by plotting the relation between $(\alpha h v)^{2}$ vs. $h v$ and extrapolating the straight line portion to the $h v$ axis. The extrapolation of linear portion to the $h v$ axis gives values of energy gap for magnesium oxide nano particles. The obtained $\mathrm{E}_{\mathrm{g}}$ values (within the range 2.91-3.12 eV) show the semiconductor nature of the samples and are in an excellent agreement with the reported data [30].

\section{Application}

Photocatalytic degradation of organic G dye: The photodegradation efficiency of selected zirconium oxide nanoparticle (sample M3; prepared from citric acid as organic precursor) was tested using Orange $\mathrm{G}(\mathrm{OG})$ as model. The experiments were done at different conditions, namely; $\left(\mathrm{UV}+\mathrm{H}_{2} \mathrm{O}_{2}+\mathrm{M} 3\right),\left(\mathrm{UV}+\mathrm{H}_{2} \mathrm{O}_{2}\right)$, (UV only), $(\mathrm{UV}+\mathrm{M} 3)$ where best results were obtained in the case of $\left(\mathrm{UV}+\mathrm{H}_{2} \mathrm{O}_{2}+\mathrm{M} 3\right)$. At periodic intervals of time, aliquots of the sample were withdrawn and the absorption spectra were recorded. Clearly, the absorbance decreases and the photodegradation efficiency increases (reaching a plateau) as a function of time (Figure 4). The results showed that the maximum percent of degradation of OG dye was $93 \%$ after 210 min indicating the very high efficiency of the nanoparticle used.

\begin{tabular}{|c|c|}
\hline Oxide & IC $_{\mathbf{5 0}}(\boldsymbol{\mu g} / \mathbf{m l})$ \\
\hline Vinblastine & 4.6 \\
\hline M2 & 213 \\
\hline M3 & 398 \\
\hline M7 & 391 \\
\hline
\end{tabular}

Table 3: Lethal concentration (IC50) of the nanosized oxides M2, Z3 and MZ7.
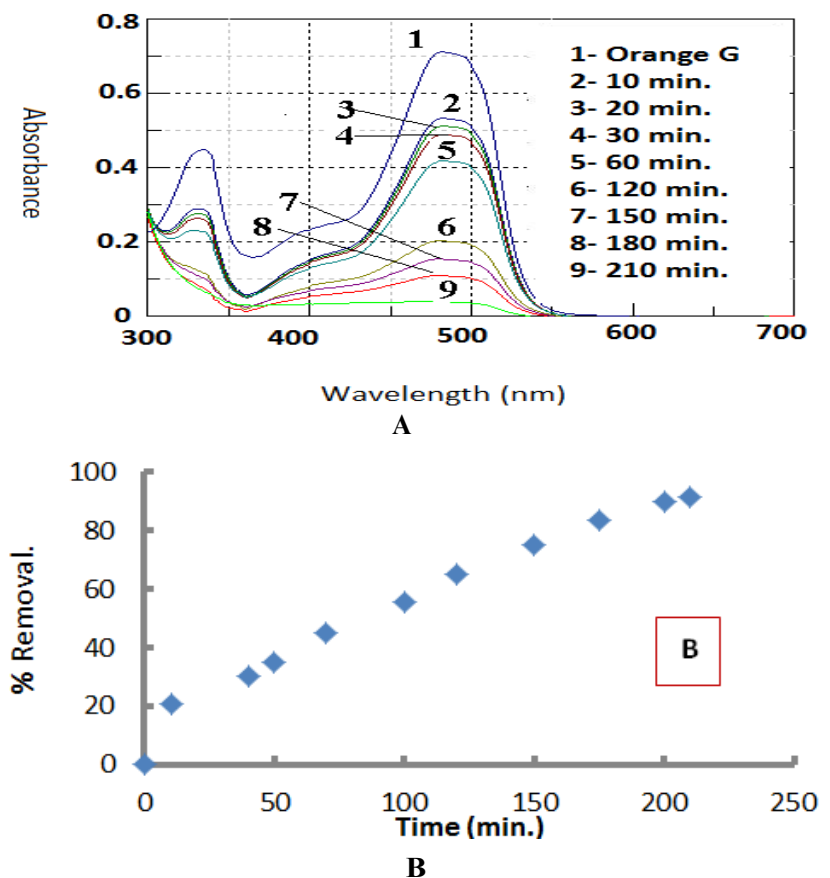

Figure 4: Effect of time on the absorption spectra (A) and \% removal (B) of OG under the influence of UV irradiation in presence of $\mathrm{H}_{2} \mathrm{O}_{2}$ and $\mathrm{M} 3$ as catalyst.

Decomposition of chemical warfare agents on metal oxides: Metal oxides demonstrate superior ability to adsorb and decompose CWA compared to pure metal surfaces. This is often attributed to reactive sites on the metal oxide surface through which organophosphonate species (nerve agents) can adsorb and subsequently undergo a hydrolysis reaction. The use of $\mathrm{MgO}$ nanoparticle, $\mathrm{M} 7$, (prepared from glycine as precursor) as catalyst for the decontamination of VX stimulant Malathion was carefully investigated. The effect of different factors affecting the removal efficiency, such as: time, $\mathrm{pH}$, temperature and initial dose of Malathion was studied. The results obtained (Figures 5 and 6) showed that such nanooxides have high ability for the removal of this pollutant from water samples.

\section{Antitumor activity}

Inhibitory activity against Breast Carcinoma MCF-7 cell line was detected using some selected nanosized metal oxides viz; M2 


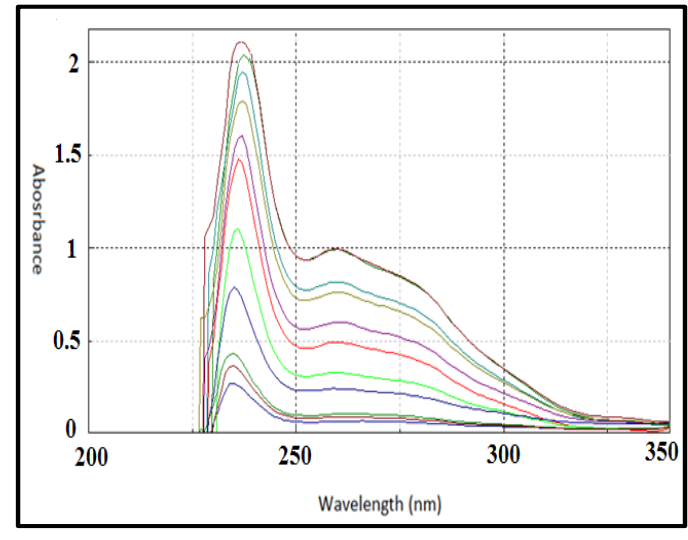

A

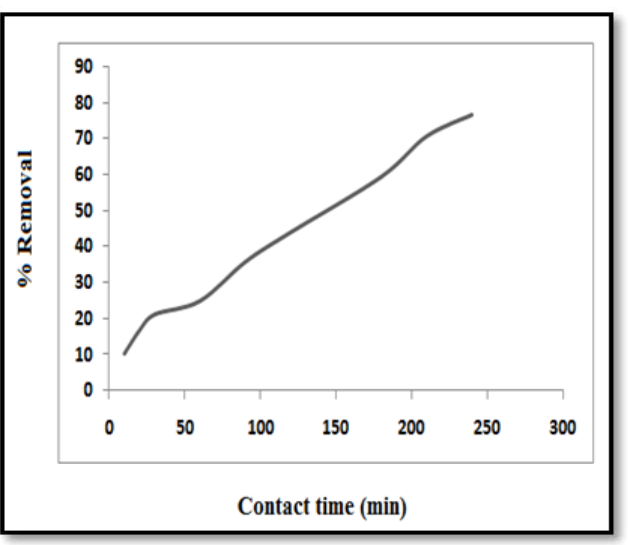

B

Figure 5: Effect of contact time on the absorption spectra of Malathion $(A)$ and its \% removal (B).

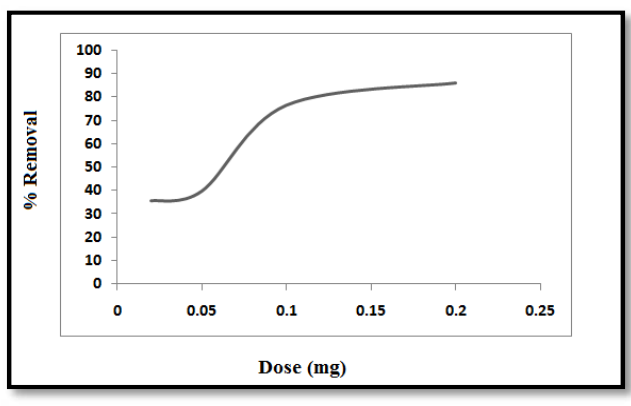

A

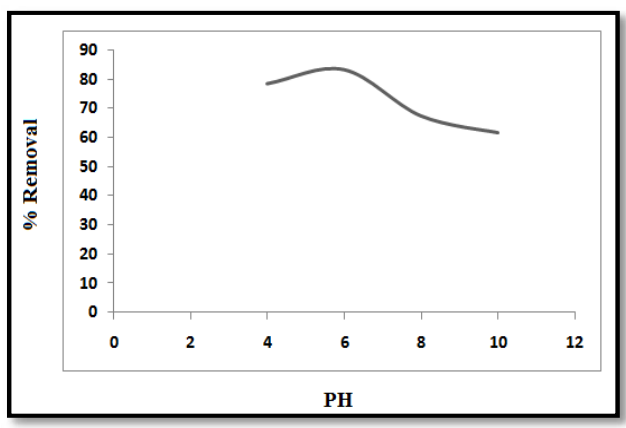

$\mathrm{C}$

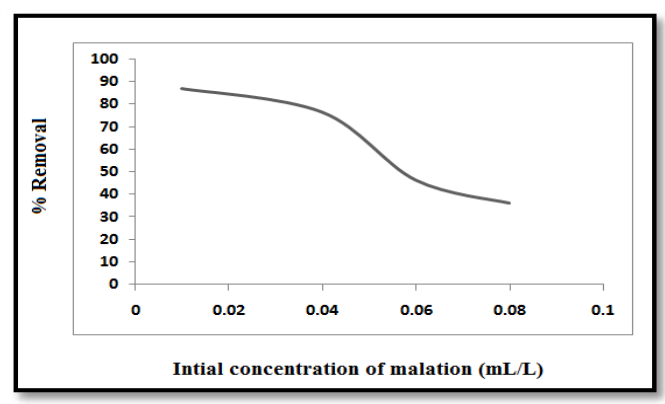

B

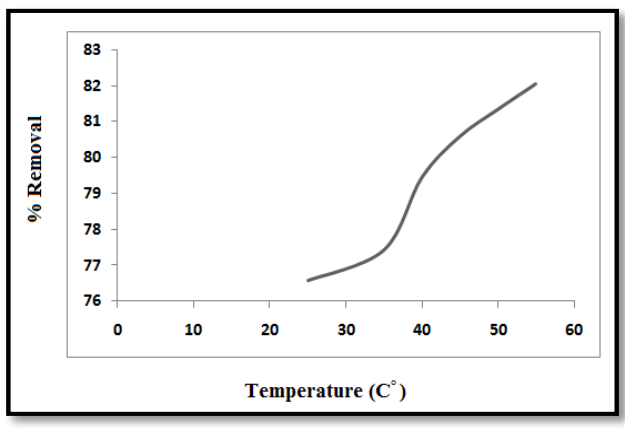

$\mathrm{D}$

Figure 6: Effect of different factors on the \% removal of Malathion; (A); adsorbent dose, (B); initial concentration, (C); pH and (D); temperature.

and M3 and M7 and compared to that of Vinblastine as a standard drug. The relation between surviving cells and drug concentration is plotted to get the survival curve of each tumor cell line after treatment with the nanooxides. The $50 \%$ inhibitory concentration $\left(\mathrm{IC}_{50}\right)$, the concentration required to cause toxic effect in $50 \%$ of intact cells, was estimated from graphic plots of the dose response curve for each concentration. The results are represented graphically in Figure 7 and the lethal concentrations $\left(\mathrm{IC}_{50}\right)$ values are listed in Table 3.

Inspection of the cytotoxic data, it is found that magnesium oxide M2 (prepared from tartaric acid) is, in general, more effective than those of M3 (prepared from citric acid) and M7 (prepared from glycine). Shier [31] suggested that compounds having $\mathrm{IC}_{50}$ values 10$25 \mu \mathrm{g} / \mathrm{ml}$ are considered to have weak cytotoxic activities, while those having intermediate values (ranging from $5-10 \mu \mathrm{g} / \mathrm{ml}$ ) are classified as moderately active. On the other hand, compounds with $\mathrm{IC}_{50}$ values less than $5 \mu \mathrm{g} / \mathrm{ml}$ are considered to be very active. Consequently, the nanosized metal oxides under study are considered to have weak activity with $\mathrm{IC}_{50}$ values higher than $213 \mu \mathrm{g} / \mathrm{ml}$.

\section{Conclusion}

$\mathrm{MgO}$ nanoparticles (M1-M7) were prepared by precipitation of $\mathrm{Mg}$ as oxalate, tartarate, citrate, succinate, malate, malonate and glycinate then ignition at $650^{\circ} \mathrm{C}$. The magnesium-organic precursors and the 
Citation: Moustafa IMI, Saleh IA, Abdelhamid MR (2017) Synthesis of MgO Nanoparticles from Different Organic Precursors; Catalytic Decontamination of Organic Pollutants and Antitumor Activity. J Material Sci Eng 6: 359. doi: 10.4172/2169-0022.1000359

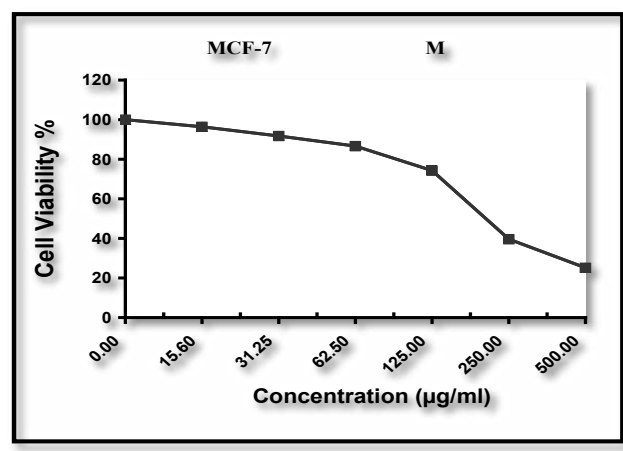

A

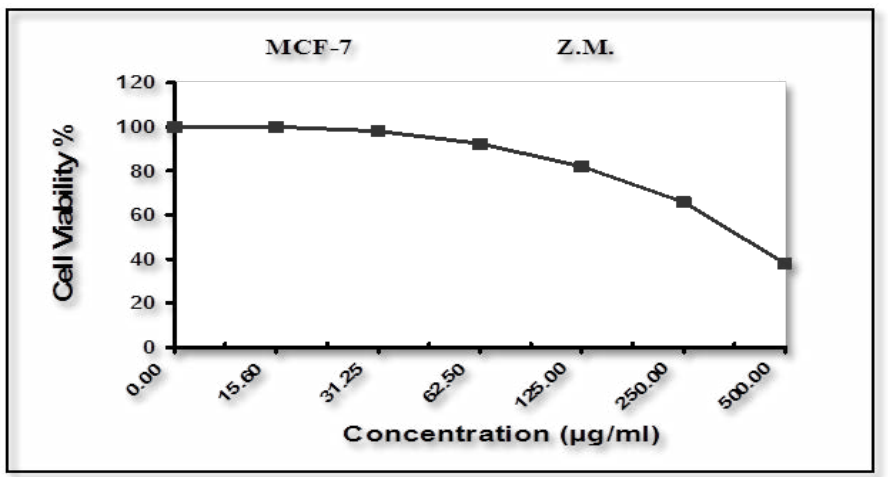

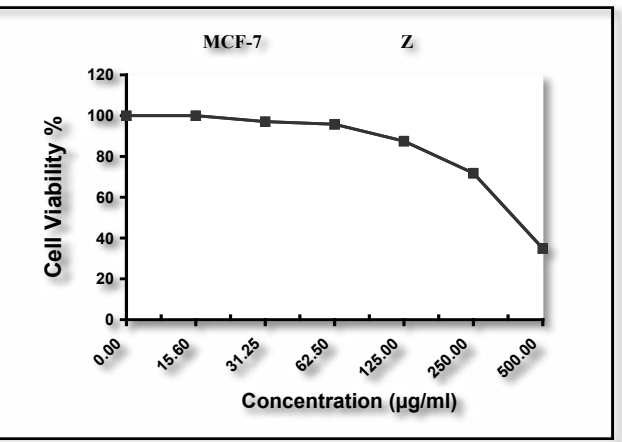

B

$\mathrm{C}$

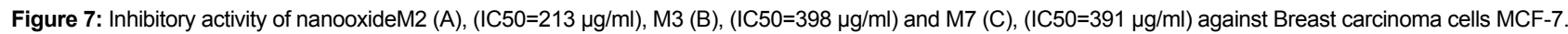

corresponding nanooxides were characterized by thermal analysis and different spectroscopic techniques. The morphology and crystal sizes were found to be highly affected by the starting organic precursors. The optical energy gaps $\left(\mathrm{E}_{\mathrm{g}}\right)$ calculated from electronic absorption spectra ranged from 2.91 to $3.12 \mathrm{eV}$ suggesting the semiconductor nature of the nanooxides. The results revealed that the prepared inexpensive magnesium oxides have high potential as catalysts for photo degradation of both Malathion and orange $G$ from water samples. Inhibitory activity against Breast Carcinoma MCF-7 cell line was detected using some selected nanosized $\mathrm{MgO}$ and compared to that of Vinblastine as a standard drug.

\section{Acknowledgement}

We would like to acknowledge the financial support from the MSP (Management of Scientific Projects), Benha University, Benha, Egypt (project presented by I. M. Ibrahim).

\section{References}

1. Neppolian B, Wang Q, Yamashita H, Choi H (2007) Synthesis and characterization of ZrO2-TiO2 binary oxide semiconductor nanoparticles: application and interparticle electron transfer process. Applied Catalysis A: General 333: 264-271.

2. Lara-García HA, Romero-Ibarra IC, Pfeiffer H (2014) Hierarchical Na-doped cubic $\mathrm{ZrO} 2$ synthesis by a simple hydrothermal route and its application in biodiesel production. Journal of Solid State Chemistry 218: 213-220.

3. Słońska A, Kaszewski J, Wolska-Kornio E, Witkowski B, Mijowska E, et al (2016) Luminescent properties of $\mathrm{ZrO} 2$ : Tb nanoparticles for applications in neuroscience. Optical Materials 59: 96-102.

4. Xiong C, Wang W, Tan F, Luo F, Chen J, et al. (2015) Investigation on the efficiency and mechanism of $\mathrm{Cd}(\mathrm{II})$ and $\mathrm{Pb}$ (II) removal from aqueous solutions using MgO nanoparticles. Journal of hazardous materials 299: 664-674.

5. Li S, Jiao Y, Wang Z, Wang J, Zhu Q, et al. (2015) Performance of RP-3 kerosene cracking over $\mathrm{Pt} / \mathrm{WO} 3-\mathrm{ZrO} 2$ catalyst. Journal of Analytical and Applied Pyrolysis 113: 736-742.

6. Renuka L, Anantharaju KS, Sharma SC, Nagaswarupa HP, Prashantha SC, et al. (2016) Hollow microspheres Mg-doped ZrO2 nanoparticles: Green assisted synthesis and applications in photocatalysis and photoluminescence. Journal of Alloys and Compounds 672: 609-622.

7. Peng W, Li J, Chen B, Wang N, Luo G, et al. (2016) Mesoporous MgO synthesized by a homogeneous-hydrothermal method and its catalytic performance on gas-phase acetone condensation at low temperatures. Catalysis Communications 74: 39-42.

8. Varshney D, Dwivedi S (2015) On the synthesis, structural, optical and magnetic properties of nano-size $\mathrm{Zn}-\mathrm{MgO}$. Superlattices and Microstructures 85: 886-893.

9. Gh AB, Sabbaghan M, Mirgani Z (2015) A comparative study on properties of synthesized $\mathrm{MgO}$ with different templates. Spectrochimica Acta Part A: Molecular and Biomolecular Spectroscopy 137: 1286-1291.

10. Klubnuan S, Amornpitoksuk P, Suwanboon S (2015) Structural, optica and photocatalytic properties of $\mathrm{MgO} / \mathrm{ZnO}$ nanocomposites prepared by a hydrothermal method. Materials Science in Semiconductor Processing 39: 515-520.

11. Li H, Li M, Qiu G, Li C, Qu C, et al. (2015) Synthesis and characterization of $\mathrm{MgO}$ nanocrystals for biosensing applications. Journal of Alloys and Compounds 632: 639-644.

12. Jin Z, Jia Y, Luo T, Kong LT, Sun B, et al. (2015) Efficient removal of fluoride by hierarchical MgO microspheres: performance and mechanism study. Applied Surface Science 357: 1080-1088

13. Ding YD, Song G, Zhu X, Chen R, Liao Q (2015) Synthesizing MgO with a high specific surface for carbon dioxide adsorption. RSC Advances 5: 30929-30935. 
Citation: Moustafa IMI, Saleh IA, Abdelhamid MR (2017) Synthesis of MgO Nanoparticles from Different Organic Precursors; Catalytic Decontamination of Organic Pollutants and Antitumor Activity. J Material Sci Eng 6: 359. doi: 10.4172/2169-0022.1000359

14. Verma R, Naik KK, Gangwar J, Srivastava AK (2014) Morphology, mechanism and optical properties of nanometer-sized $\mathrm{MgO}$ synthesized via facile we chemical method. Materials Chemistry and Physics 148: 1064-1070.

15. Yadav LR, Lingaraju K, Manjunath K, Raghu GK, Kumar KS, et al. (2017) Synergistic effect of $\mathrm{MgO}$ nanoparticles for electrochemical sensing, photocatalytic-dye degradation and antibacterial activity. Materials Research Express 4: 025028.

16. Devaraja PB, Avadhani DN, Prashantha SC, Nagabhushana H, Sharma SC et al. (2014) Synthesis, structural and luminescence studies of magnesium oxide nanopowder. Spectrochimica Acta Part A: Molecular and Biomolecular Spectroscopy 118: 847-851.

17. Moussavi G, Mahmoudi M (2009) Removal of azo and anthraquinone reactive dyes from industrial wastewaters using $\mathrm{MgO}$ nanoparticles. Journal of Hazardous Materials 168(2): 806-812.

18. Moussavi G, Mahmoudi M (2009) Degradation and biodegradability improvement of the reactive red 198 azo dye using catalytic ozonation with $\mathrm{MgO}$ nanocrystals. Chemical Engineering Journal 152: 1-7.

19. Bindhu MR, Umadevi M, Micheal MK, Arasu MV, Al-Dhabi NA (2016) Structural, morphological and optical properties of $\mathrm{MgO}$ nanoparticles for antibacterial applications. Materials Letters 166: 19-22.

20. Hamdy MS, Awwad NS, Alshahrani AM (2016) Mesoporous magnesia: Synthesis, characterization, adsorption behavior and cytotoxic activity. Materials \& Design 110: 503-509

21. Rao PV, Nallappan D, Madhavi K, Rahman S, Jun Wei L, et al. (2016) Phytochemicals and biogenic metallic nanoparticles as anticancer agents. Oxidative medicine and cellular longevity.
22. Krishnamoorthy K, Manivannan G, Kim SJ, Jeyasubramanian K, Premanathan $\mathrm{M}$ (2012) Antibacterial activity of MgO nanoparticles based on lipid peroxidation by oxygen vacancy. Journal of Nanoparticle Research 14: 1063.

23. Tang ZX, Lv BF (2014) MgO nanoparticles as antibacterial agent: preparation and activity. Brazilian Journal of Chemical Engineering 31: 591-601.

24. Yadav LR, Lingaraju K, Manjunath K, Raghu GK, Kumar KS, et al. (2017) Synergistic effect of $\mathrm{MgO}$ nanoparticles for electrochemical sensing photocatalytic-dye degradation and antibacterial activity. Materials Research Express 4: 025028.

25. Ibrahim IM, Moustafa ME, Abdelhamid MR (2016) Effect of organic acids precursors on the morphology and size of $\mathrm{ZrO} 2$ nanoparticles for photocatalytic degradation of Orange $G$ dye from aqueous solutions. Journal of Molecular Liquids 223: 741-748.

26. Yua J, Kimb D (2013) Powder Tech 235: 1030-1037.

27. Motlagh MK, Youzbashi AA, Sabaghzadeh L (2011) Synthesis and characterization of Nickel hydroxide/oxide nanoparticles by the complexationprecipitation method. International Journal of Physical Sciences 6: 1471-1476.

28. Arora K, Devi S (2012) current trends in biotech and chem. Research 2.

29. Chang-Sam K, Dond-Hun Y, Sung-Woon J, Hyok-Bo K, Sang-Hwan P (2010) J Korean Cryst, Growth Cryst Tech 20: 283-288.

30. Dhere SL (2015) Silica-zirconia alkali-resistant coatings by sol-gel route. Curr Sci 108: 1647-1652.

31. Shier WT (1991) Mammalian cell culture on $\$ 5$ a day: a laboratory manual of low cost methods. Los Banos, University of the Philippines 64: 9-16. 